\title{
Experimental Investigation of Separation Angle of Interflow Dense Current from Bed
}

\author{
Leila Hashemi ${ }^{1}$, Mehdi Ghomeshi ${ }^{2 *}$
}

1- M.Sc. Graduated Student, Department of Water Structures, Shahid Chamran University of Ahvaz. (Leila_hashemi20@yahoo.com)

$2^{*}$ - Corresponding Author, Professor, Department of Water Structures, Shahid Chamran University of Ahvaz.

\begin{abstract}
When a dense flow reaches neutral buoyancy in the stratified ambient fluid, it can leave the slope and enter the ambient fluid as an interflow. In this study, the effect of discharge and concentration variations on the separation angle of the dense current body at the separation point was investigated using a physical model. The results showed that for all slopes, the separation angle of the dense current body relative to the angle of the flume bed and the horizon (bed slope angle) increased with increasing the inflow rate of the dense current at a constant concentration and decreased with increasing the concentration of the dense current at a constant discharge. On the other hand, for all states, the angle of dense current separation with the bed was always larger than the angle of the flume bed with the horizon.
\end{abstract}

Keywords: Turbidity current, Separation point, Separation angle of the turbidity current.

\section{Introduction}

Dense currents are created due to difference in the density between different fluid layers. This difference in density, which is the main driving force of the flow, can arise from temperature difference, soluble materials, or insoluble particles (suspended particles). These currents are flowing due to the effect of gravity on the difference of density between the two fluids. Three different kinds of flow diffusion into the reservoir have been widely recognized: overflow, interflow, and underflow. The type of flow depends on the difference between the density of the inflow and the standing reservoir's fluid (An and Julien, 2014). Flows denser than the ambient standing fluid flow along the bed slope as the underflow. If the density of inflow is less than the ambient fluid, an outflow is formed and travels on the fluid surface. In case, the ambient fluid has a stratified density, so that densities in the surface and floor are less and more than the dense inflow, respectively, and the flow is separated from the bed and intrudes almost horizontally into the fluid, as the interflow. Intrusion occurs where buoyancy is neutralized (Cortés et al., 2014). A density current within a stratified environment is known as intrusive gravity currents IGC, which travel horizontally at a roughly constant velocity $U$ within the stratified layer after propagation (Nokes et al., 2008). Figure 1 shows density flow regimes of flood-induced turbidity flows in the stratified reservoir of Korea (An, (2011)).

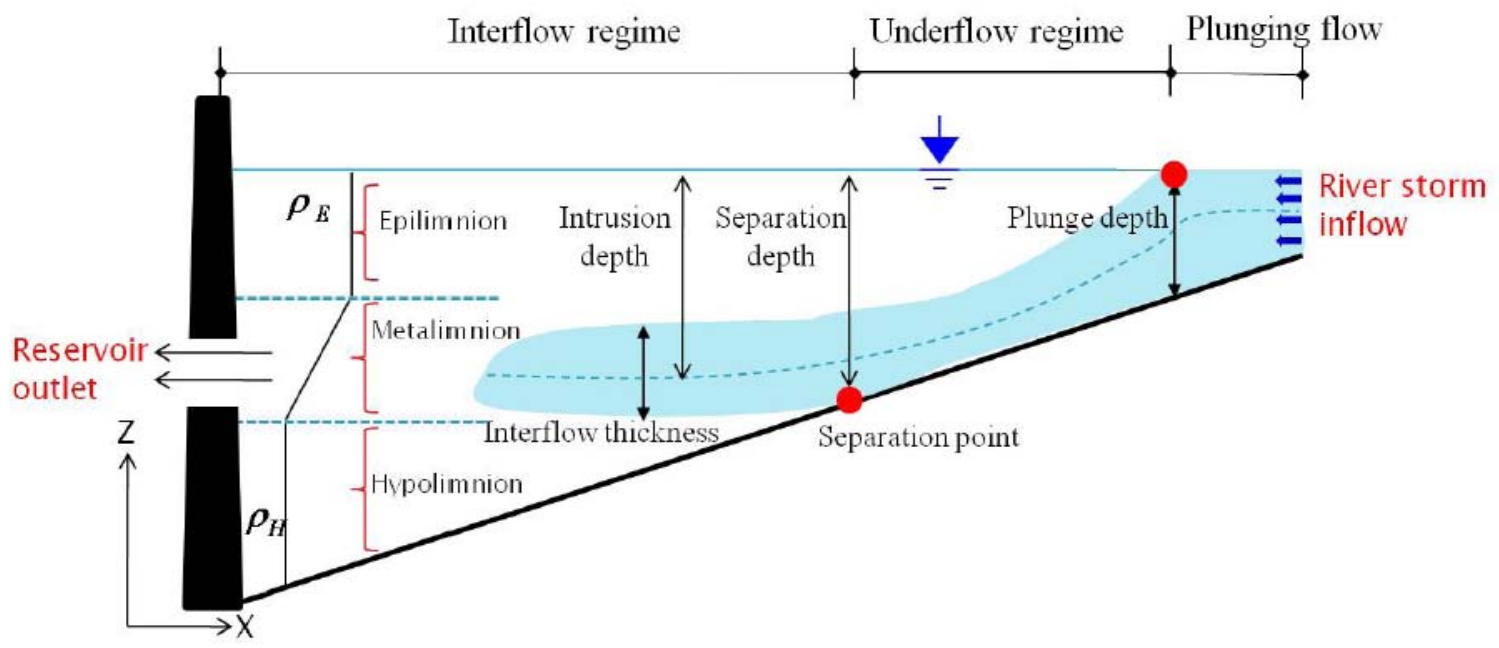

Figure 1. Density flow regimes of flood-induced turbidity flows in a stratified reservoir (An, (2011)).

Adams et al., (1975) and Safaie (1979) produced overflow through heat exchangers in their studies. Kao (1977) deduced the propagation velocity along a common (sharp) surface between two homogeneous fluids based on Bernoulli's principle. Holyer and Huppert (1980) expanded the theory presented by Benjamin (1968) to describe 
the stratified density fluid dynamics. Wells and Nadarajah, (2009) found that the mixing rate is effective in the flow deformation state. They provided the theory and conducted lab experiments to describe the depth where the dense current intrudes into a linear stratified fluid layer. An and Julien, (2014) examined the dynamics of dense current intrusion into the Imha reservoir in North Korea through numerical methods. The results of simulation showed that if the concentration of turbidity fluid exceeds $2000 \mathrm{mg} / \mathrm{L}$, the river flow can be formed as an interflow in the summer months. Zhang et al., (2015) investigated the effect of thermal stratification created in a reservoir on the travel time of the pollutant interflow; they simulated the leakage of the pollutant into the reservoir through sudden diffusion of a stream into a stratified reservoir and predicted the interflow velocity through dimensional analysis based on the energy conservation law and eventually provided a linear relationship between the travel time and buoyancy.

The separation angle of the interflow dense current through the bed has not been investigated so far by researchers. Therefore, in the present study, the intrusion of dense current into a saline stratified fluid was investigated using a physical model.

\section{Materials and Methods}

In order to carry out the experiments, a flume of $9 \mathrm{~m}$ length, $0.34 \mathrm{~m}$ width, and $0.70 \mathrm{~m}$ height was made of plexiglass with a variable bed slope. The flume was longitudinally divided into two sections using a sliding gate at one meter from the beginning of the flume. The chamber behind the gate was used as the inlet of the turbidity current and the chamber at the front of the gate as the reservoir of the ambient standing fluid. A schematic representation of the flume and the inlet gate is shown in Fig. 2.

With the entrance of clear water, salinity did not remain on the floor and moved upward due to the diffusion phenomenon. Therefore, after a certain time, a stratified saline fluid was created so that the intensity of salinity was reduced from the floor toward the water surface. After formation of the fluid with saline stratification, the salinity level at different flume cross-sections was measured by using the digital EC meter. In addition, the turbidity fluid was prepared in a separate reservoir according to the characteristics in Table 1 and, within a short time after collecting the salinity values, it was introduced into the chamber behind the gate through the inlet gate with a specified discharge. The variables that are used in this study are provided in table2.

Table 1. Properties of the sediments used in the experiment

\begin{tabular}{cccc}
\hline $\begin{array}{c}\text { Geometric standard } \\
\text { deviation }\left(\sigma_{\mathrm{g}}\right)\end{array}$ & $\begin{array}{c}\text { Relative density } \\
(\mathrm{Gs})\end{array}$ & Mean diameter & Sediment material \\
\hline 4.8 & 2.67 & 6.88 micron & $\begin{array}{c}\text { Non-uniform } \\
\text { silica }\end{array}$ \\
\hline
\end{tabular}

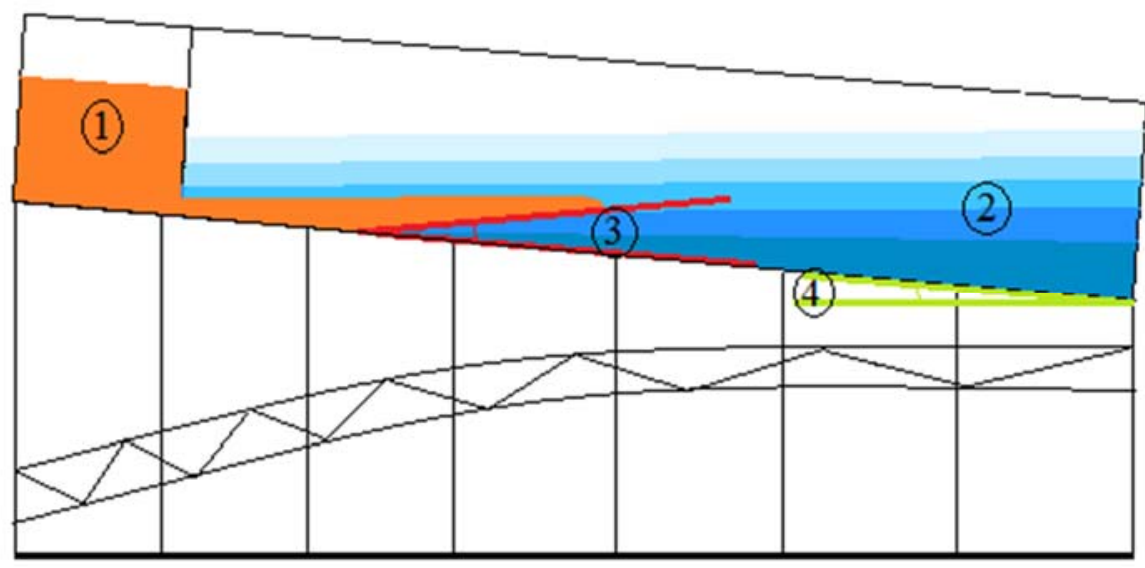

Figure 2. A schematic representation of the flume and the inlet gate 
Table 2. Specification of Variables Used in this study

\begin{tabular}{ccc}
\hline Number & Symbol & Parameters \\
\hline 1 & - & Reservoir of the turbidity current \\
2 & - & The fluid with saline stratification \\
3 & $\alpha$ & The separation angle of the dense current body \\
4 & $\theta$ & The angle of bed slope \\
\hline
\end{tabular}

When the turbidity fluid in the container reach to the same height as that of the ambient fluid in the flume, the sliding gate was immediately opened to allow the turbidity current enter the flume with saline stratification fluid. In this case, the sedimentary density current initially moved as an underflow current due to its heavier weight compared to the surrounding fluid layers. When the current reach to layer with same density, the turbidity current was separated from the flume floor and penetrated the surrounding fluid as an interflow density current. A summary of the experiments conducted in this project is provided in Table 3.

Table 3. A summary of the experiments conducted in this research

\begin{tabular}{ccllllllll}
\hline Number & (\%) Slope & \multicolumn{3}{c}{ Discharge $(1 / \mathrm{s})$} & \multicolumn{4}{c}{ Concentration $(\mathrm{g} / \mathrm{l})$} \\
\hline 16 & 2.5 & 1 & 1.5 & 2 & 2.5 & 5 & 10 & 15 & 20 \\
16 & 3.25 & 1 & 1.5 & 2 & 2.5 & 5 & 10 & 15 & 20 \\
16 & 4 & 1 & 1.5 & 2 & 2.5 & 5 & 10 & 15 & 20 \\
\hline
\end{tabular}

\section{Discussion and results}

\section{Distribution of salinity in the ambient fluid}

In order to study the distribution of salinity in the flume, the salinity values of 7 different flume sections were plotted against the ambient fluid height for each of the 3 slopes shown in Figures 3-5. According to these curves, it is observed that the salinity layer formed in the flume has an increasing trend from the surface of the ambient fluid to the flume bed, so that the lowest level of salinity was observed at the surface and the salinity increased when approaching the bed of the flume and reached the maximum amount on the floor. On the other hand, due to the slope of the flume and intrusion of the initial salinity to one meter from the gate, the salinity of the bed differed from the beginning to the end of the flume and has increased from the gate toward the end of the flume. So that the salinity level was very low at distances close to the gate, and slight changes were observed in the collected salinities from the surface to the flume floor. In fact, layers with lesser density, close to the density of clear urban water, were created near the gate. Changes in salinity can be considered almost linear at the beginning of the flume. But at distances far from the gate and close to the middle of the flume, not only the fluid salinity increased at the flume floor, but also the range of variation increased from the surface to the flume bed. According to the curves, the variations were not linear and increased sharply. This sharp increase can be attributed to the boundary between the saline water pumped into the flume and the clean urban water.

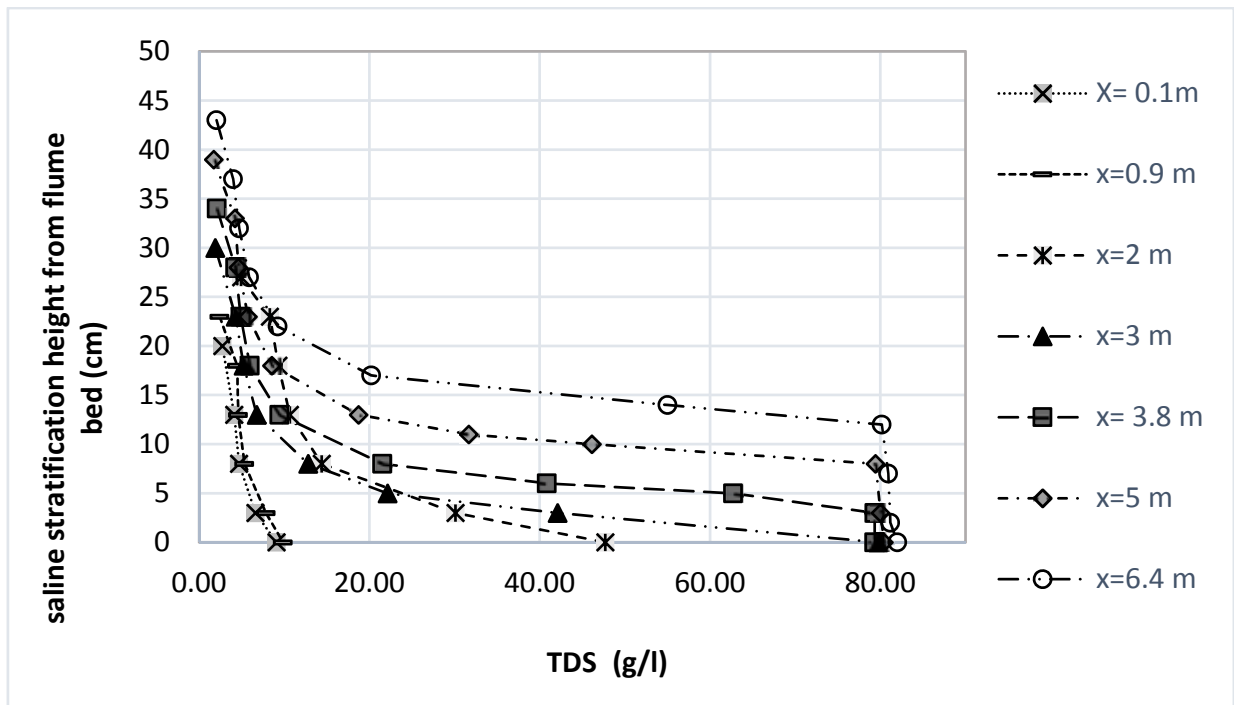

Figure 3. Salinity layer formed in flume with bed slope of $4 \%$ 


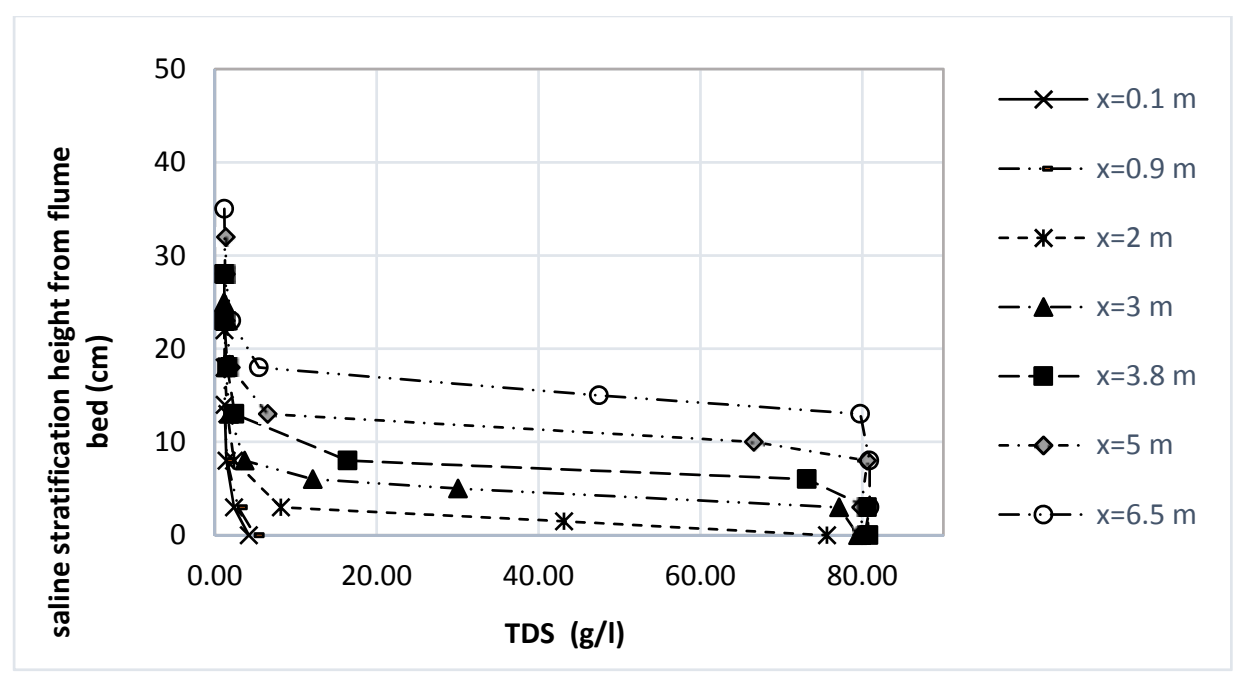

Figure 4. Salinity layer formed in flume with bed slope of $3.25 \%$

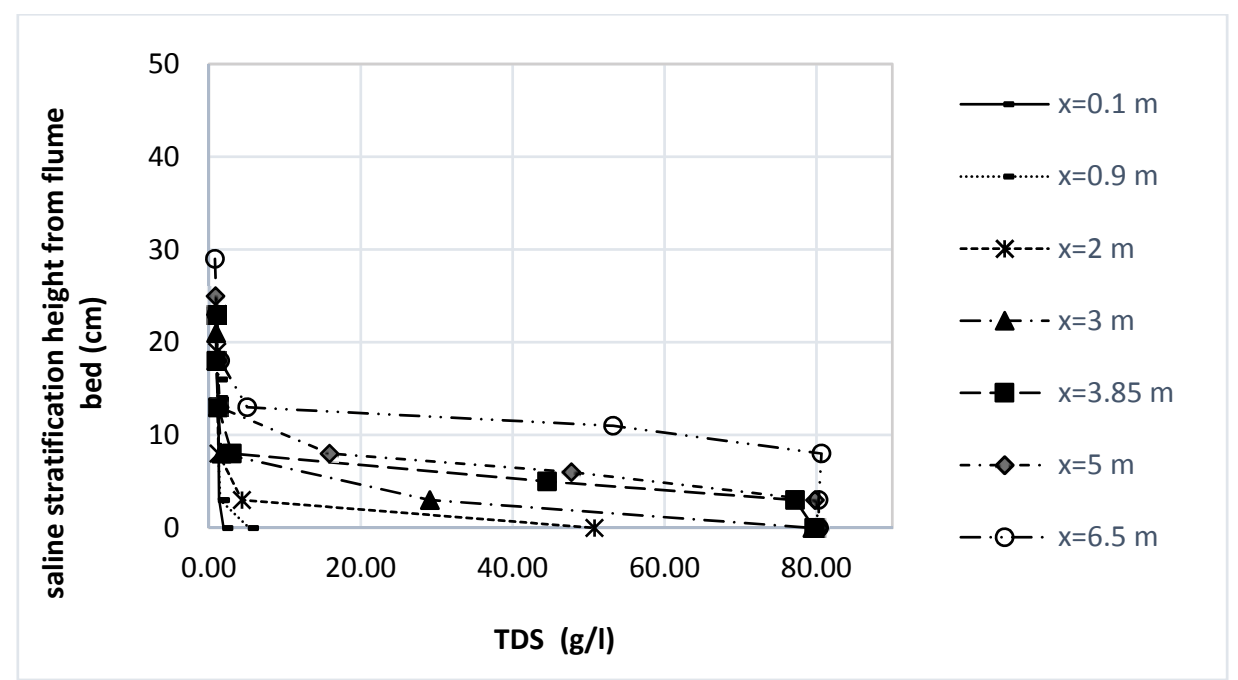

Figure 5. Salinity layer formed in flume with bed slope of $2.5 \%$

By increasing the flume bed slope, the volume of saline water pumped into the flume increased, and hence, the clean urban water released over it had a higher height, which increased the time of fresh water inflow into the flume. As a result, this provided more time for the distribution of salinity under the diffusion phenomenon, increasing the density of layer height and the depth of each layer with constant density. In other words, decreasing the slope reduced the time for distribution of salinity through reducing the saline water volume pumped into the flume and reducing the final depth of the ambient fluid near the gate, resulting in formation of a low altitude density layer at the boundary.

\section{The density current separation angle}

According to the experiments carried out based on Table 1, the dense current separation angle from the bed $(\alpha)$ changed due to the effects of variations in the concentration and discharge of the turbidity fluid. Therefore, in order to investigate these changes, the values of the parameter $(\alpha / \theta)$, which indicate the ratio of the dense current body separation angle $(\alpha)$ relative to the flume bed angle with the horizon $(\theta)$, were separately measured versus the discharge and concentration variations. The results are presented in this paper.

In order to investigate the effect of discharge on the separation angle, the measured values of $\alpha / \theta$ versus the variations of discharge in different slopes and all concentrations are shown in Fig. 6. As can be seen, the value of $\alpha / \theta$ is greater than one in all concentrations. This means that the dense current is always separated at the separation point, with angles larger than the bed slope. It is also observed that with increasing the discharge at a steady concentration, the value of $\alpha / \theta$ increased for all slopes; the changes trend can be considered linear. In other words, by increasing the discharge, the current separation angle increased compared to the flume bed angle. In fact, by increasing the discharge, the momentum of the current increased and the separation occurs in greater salinity, causing a difference in concentration between the flow separation point and the flow same-dense layer, thus, to reach the same-dense level, the dense current was separated with a larger angle from the bed. On average, with 
increasing discharge from $1 \mathrm{~L} / \mathrm{s}$ to $2.5 \mathrm{~L} / \mathrm{s}$, the ratio of $\alpha$ to $\theta$ for concentrations of $5,10,15$, and $20 \mathrm{~g} / \mathrm{L}$ was increased by $1.36,1.42,1.49$, and 1.57 times, respectively, for all slopes.

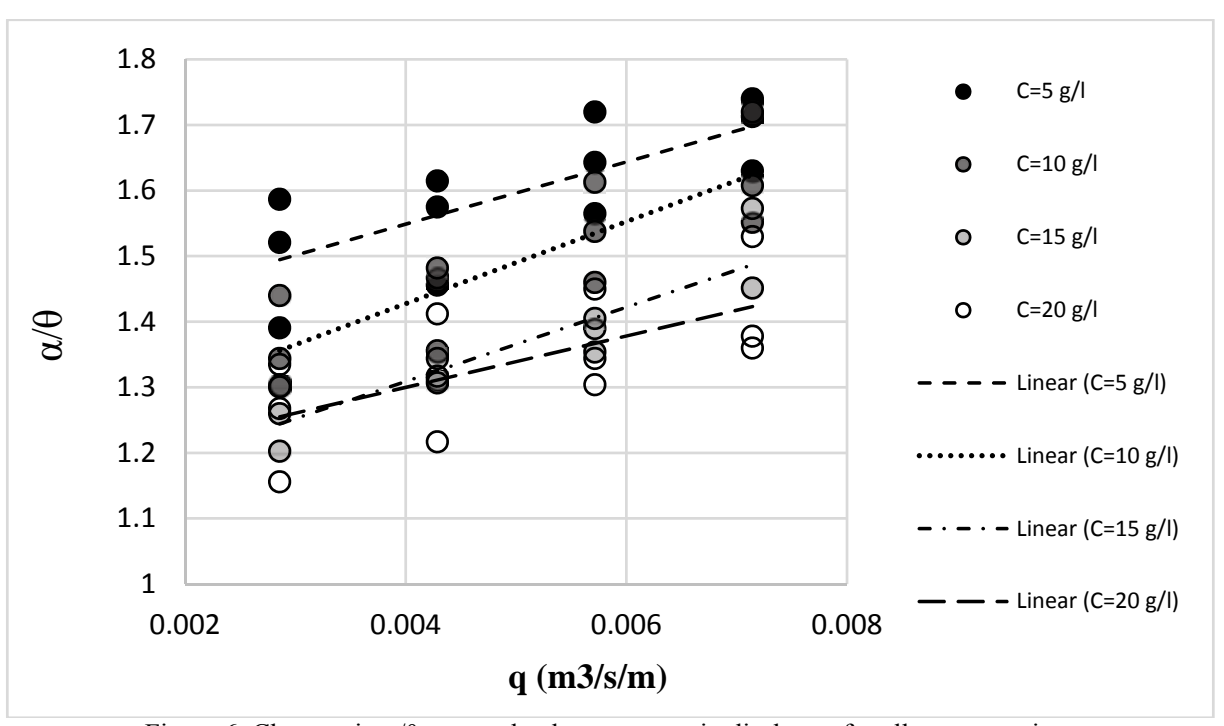

Figure 6. Changes in $\alpha / \theta$ versus the dense current in discharge for all concentrations

Figure 7 shows the values of $\alpha / \theta$ versus increasing concentrations for all slopes and all discharges. It was observed that for all cases, with increasing concentration of the dense current inflow, changes in $\alpha / \theta$ had a decreasing trend, meaning that as the concentration increased, the flow separated from the bed with a smaller angle. Since the separation of the flow from the bed occurred where the flow density was approximately equal to the ambient fluid, by increasing the concentration of the current, rising was expected to occur in a place with more salinity. On the other hand, since the slope of the concentration variations was more intense in the lower layers of the stratified fluid and the layers had a more compact thickness, therefore, the density current was separated from the bed with a smaller angle to reach the same dense layer and intrude into the ambient fluid. On average, with increasing concentrations of the density current from $5 \mathrm{~g} / \mathrm{L}$ to $10 \mathrm{~g} / \mathrm{L}$, the ratio of $\alpha$ to $\theta$ for discharges of $1,1.5,2$, and 2.5 $\mathrm{L} / \mathrm{s}$ was increased by $1.6,1.5,1.36$, and 1.34 times, respectively, for all slopes.

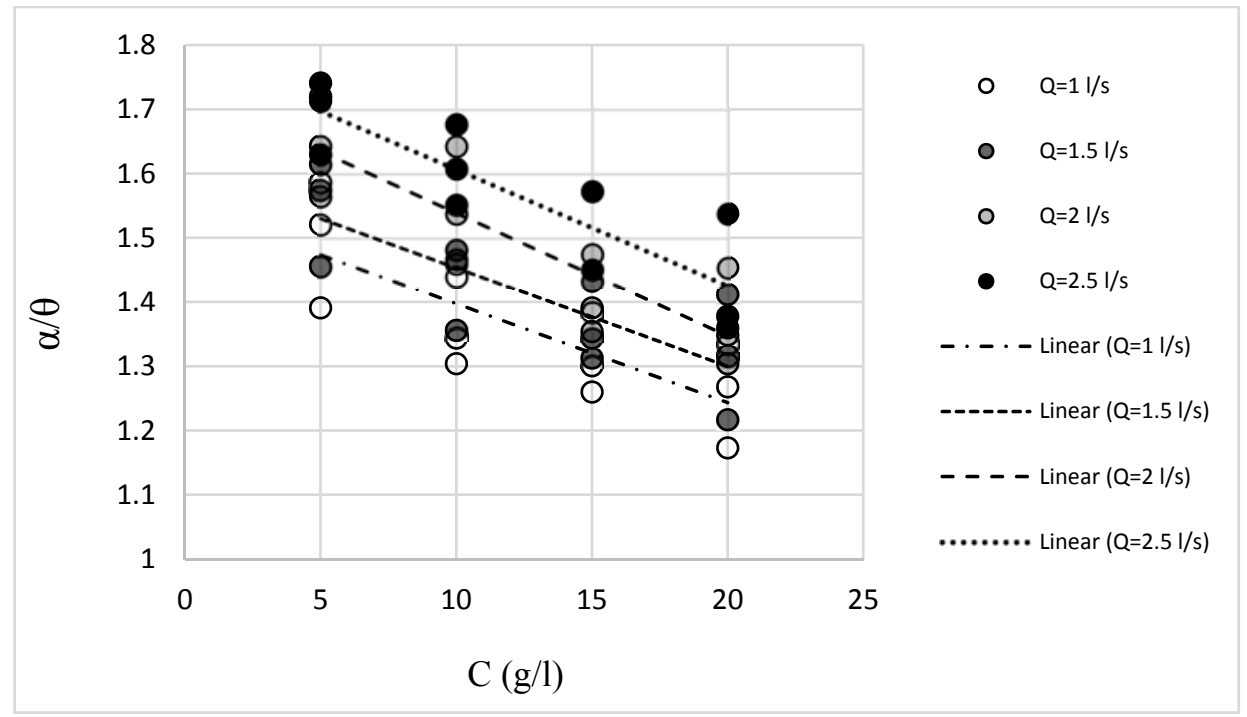

Figure 7. Changes in $\alpha / \theta$ versus the dense current in concentrations for all discharge

\section{Conclusion}

The results of this study, which was carried out to study the separation angle of the dense current interflow at the point of separation from the bed, showed that, for all cases, the dense current separation angle was larger than the flume bed angle, and $\alpha / \theta$ was always larger than one. In addition, the effect of discharge and concentration variations on $\alpha / \theta$ was also studied and it was found that with increasing the discharge at a steady concentration for all slopes, the $\alpha / \theta$ ratio increased linearly. In other words, with increasing the discharge, the dense current separation angle increased compared to the flume bed angle. On the other hand, by increasing the concentration 
of the dense current inflow in a constant flow for all slopes, the dense current separated from the bed with a smaller angle, and changes in $\alpha / \theta$ had a decreasing trend.

\section{References}

[1] Adams, E.E., Harleman, D.R. and Stolzenbach, K.D., 1975. Near and far field analysis of buoyant surface discharges into large bodies of water. Ralph M. Parsons Laboratory for Water Resources and Hydrodynamics.

[2] An, S.D., 2011. Interflow dynamics and three-dimensional modeling of turbid density currents in Imha Reservoir, South Korea (Doctoral dissertation, Colorado State University. Libraries).

[3] An, S. and Julien, P.Y., 2014. Three-dimensional modeling of turbid density currents in Imha Reservoir, South Korea. Journal of hydraulic engineering, 140(5), p.05014004.

[4] Benjamin, T.B., 1968. Gravity currents and related phenomena. Journal of Fluid Mechanics, 31(2), pp.209-248.

[5] Cortés, A., Rueda, F.J. and Wells, M.G., 2014. Experimental observations of the splitting of a gravity current at a density step in a stratified water body. Journal of Geophysical Research: Oceans, 119(2), pp.1038-1053.

[6] Holyer, J.Y. and Huppert, H.E., 1980. Gravity currents entering a two-layer fluid. Journal of Fluid Mechanics, 100(4), pp.739-767.

[7] Kao, T.W., 1977. Density currents and their applications. Journal of the Hydraulics Division, 103(ASCE 12947).

[8] Nokes, R.I., Davidson, M.J., Stepien, C.A., Veale, W.B. and Oliver, R.L., 2008. The front condition for intrusive gravity currents. Journal of Hydraulic Research, 46(6), pp.788-801.

[9] Safaie, B., 1979. Mixing of buoyant surface jet over sloping bottom. Journal of the Waterway, Port, Coastal and Ocean Division, 105(4), pp.357-373.

[10] Wells, M. and Nadarajah, P., 2009. The intrusion depth of density currents flowing into stratified water bodies. Journal of Physical Oceanography, 39(8), pp.1935-1947.

[11] Zhang, X.F., Ren, S., Lu, J.Q. and Lu, X.H., 2015. Effect of thermal stratification on interflow travel time in stratified reservoir. Journal of Zhejiang University-SCIENCE A, 16(4), pp.265-278. 